\title{
Choice of postoperative radiation for stage IIIA pathologic N2 non-small cell lung cancer: impact of metastatic lymph node number
}

Siwei Wang ${ }^{1,2+}$, Zhifei Ma ${ }^{1,2+}$, Xiangbao Yang ${ }^{3+}$, Yajing Wang ${ }^{2}$, Youtao X $\mathbf{u}^{1}$, Wenjia Xia ${ }^{1,2}$, Rui Chen ${ }^{2,4}$, Mantang Qiu', Feng Jiang ${ }^{1}$, Rong Yin ${ }^{1}$, Lin $\mathrm{Xu}^{1 *}$ and Keping $\mathrm{Xu}^{{ }^{3 *}}$

\begin{abstract}
Background: Postoperative radiation (PORT) is an option for non-small cell lung cancer (NSCLC) patients with resectable stage IIIA pathological N2 status (pN2). For patients with PORT, this study aims to investigate the impact of the exact number of positive lymph nodes (LNs) on overall survival (OS) and lung cancer-specific survival (LCSS).

Methods: Within the Surveillance, Epidemiology, and End Results database, we identified 3373 patients with stage IIIA pathological N2 status (pN2) NSCLC who underwent a lobectomy or pneumonectomy from 2004 to 2013. OS and LCSS were compared among patients coded as receiving PORT or observation. The proportional hazards model was applied for investigation.

Results: OS and LCSS favored PORT for patients with stage IIIA (pN2) NSCLC. Multivariable analyses showed that PORT and the exact number of positive LNs $(n \leq 3)$ were independently associated with better OS and LCSS. Both better OS and LCSS emerged for positive LNs $(n>3)$ after the use of PORT in survival analyses, whereas the benefits of OS and LCSS were not observed anymore for positive LNs $(n \leq 3)$ group. More importantly, multivariable analyses showed that the use of PORT is an independent risk factor of survival for positive $L N s(n>3)$ but not for positive LNs $(n \leq 3)$.
\end{abstract}

Conclusions: In Stage IIIA (pN2) NSCLC, the use of PORT demonstrated better survival results than no PORT for patients with positive LNs $(n>3)$, but not for patients with positive LNs $(n \leq 3)$.

Keywords: Postoperative radiotherapy (PORT), Non-small cell lung cancer (NSCLC), Lymph nodes (LNs)

\section{Background}

The presence of histologically confirmed lymph node metastases is an important prognostic factor for many malignancies. In non-small cell lung cancer (NSCLC), the nodal status with metastases has been suggested to be of significance. For patients with pathologic N2

\footnotetext{
* Correspondence: xulin83cn@gmail.com; keping_xu@163.com

${ }^{\dagger}$ Equal contributors

'Department of Thoracic Surgery, Jiangsu Cancer Hospital \& Jiangsu Institute of Cancer Research \& Nanjing Medical University Affiliated Cancer Hospital, Jiangsu Key Laboratory of Molecular and Translational Cancer Research, Nanjing 210009, China

${ }^{3}$ Department of Thoracic Surgery, Huai'an First People's Hospital, Nanjing Medical University, Huai'an 223300, China

Full list of author information is available at the end of the article
}

NSCLC that is considered resectable, complete surgical resection is a favor choice of the management of localized non-small-cell cancer and the use of adjuvant platinum-based chemotherapy is also considered the standard of care presently $[1,2]$.

However, even after complete surgical resection and adjuvant chemotherapy, node-positive patients still have a $20 \%$ to $40 \%$ risk of localregional recurrence (LRR), and LRR correlates independently with worse OS for patients with NSCLC $[2,3]$. Thus, postoperative radiation therapy (PORT) is often recommended to improve local tumor control and survival in IIIA (N2) NSCLC patients with good performance status. Additionally, for resectable stage IIIA N2 patients, National Comprehensive 
Cancer Network (NCCN) guidelines (Version4. 2016) also support the use of PORT (sequential or concurrent chemoradiation) for $\mathrm{N} 2$ nodal status patients regardless of whether the surgical margins are positive. Two singlecenter retrospective studies and one previous SEER based study suggested that the use of PORT improved survival for patients with N2 nodal disease [4-6]. Another postoperative trial also demonstrated a benefit to PORT in N2 disease [7]. However, a previous metaanalysis of randomized trials demonstrated no benefit with PORT, and the use of PORT could even result in a decrease in OS due to the cardiac and pulmonary toxicity from the radiotherapy itself [8]. In addition, a recent randomized trial refer to whether PORT is benefit or not for N2 NSCLC patients (NCT00410683, Lung ART in Paris) is still recruiting patients, which indicates that PORT or not was still a controversial issue.

In NSCLC, the number of nodal stations with metastases has been previously demonstrated to have significances on the survival of $\mathrm{N} 2$ diseases with PORT [9, 10]; however, few studies focused on the numbers of positive LNs, and so far only one singlecenter study demonstrated the total number of positive LNs seems to be an independent prognostic indicator in patients with pN2 NSCLC [11]. Therefore, it is valuable to further analyze whether the number of positive LNs could impact the prognosis in $\mathrm{pN} 2$ patients with PORT.

\section{Methods}

\section{Data collection}

The Surveillance, Epidemiology, and End Results (SEER) database is a national cancer surveillance program that collects information on all incident cancer cases from 18 areas of United States and covers approximately $26 \%$ of the population. In this study, identified data for patients with stage IIIA pathological N2 NSCLC were obtained from the SEER database for patients treated from January 2004 to December 2013. Pathologic IIIA stage patients derived from AJCC stage group (6th and 7th edition). N2 LNs status were defined according to CS LNs codes manual. The specific histologic types selected were those coded as non-small cell carcinoma, large cell carcinoma NOS, adenocarcinoma NOS and squamous cell carcinoma NOS. We then only chose patients with positive LNs according to regional nodes positive codes. Patients were finally included if they underwent a radical surgery of either a lobectomy or pneumonectomy. Subsequently, only those patients coded as receiving no radiation and/or cancer-directed surgery were considered not treated by postoperative radiotherapy, and those who coded as radiation after surgery were defined treated by postoperative radiotherapy. Radiation method was then restricted to beam radiation and radiation
NOS according to radiation codes. Overall survival (OS) and lung cancer-specific survival (LCSS) were determined from SEER cause-specific death classification and SEER other cause of death classification codes. OS was defined as the time from surgery until death as a result of any cause, and LCSS was defined as the interval from surgery until death as a result of lung cancer. To reduce the immortal time bias, we excluded patients who survived less than 4 months. Fig. 1 details the selection process for inclusion of patients.

Categoric variables included patient age at diagnosis ( $<65 \mathrm{v} . \geq 65$ years), sex, race, location (main bronchus, upper lobe, middle lobe, lower lobe, overlapping and unspecified), tumor size $(\leq 3.0,3.1$ to $5 \cdot 0,5.1$ to $7 \cdot 0$,

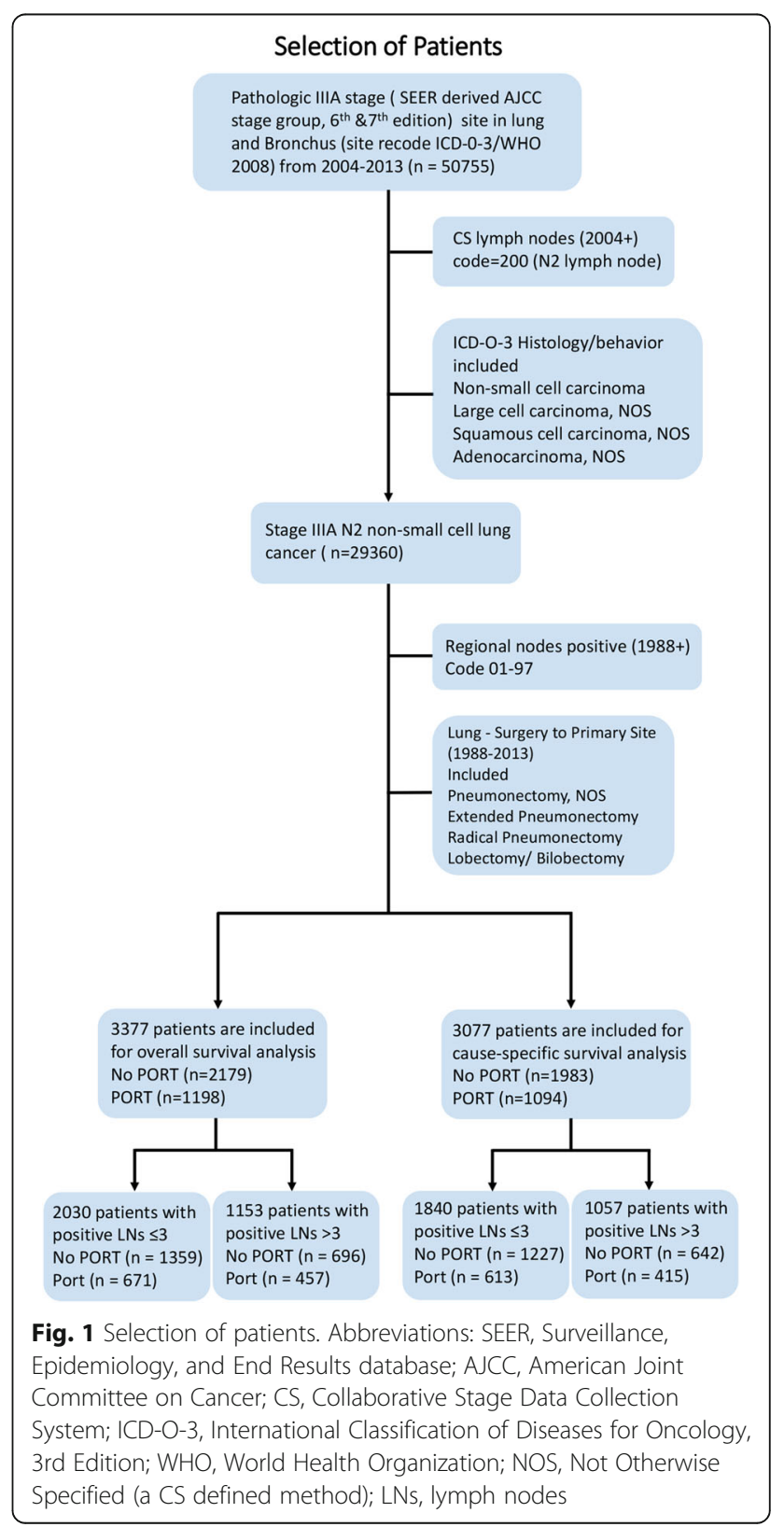


$\geq 7.0 \mathrm{~cm}$ and unknown), $\mathrm{T}$ stage (T1, T2, T3 and Tx), laterality (right, left and unspecified), histology (non-small cell carcinoma, adenocarcinoma NOS, squamous cell carcinoma, NOS and large cell carcinoma NOS), surgery type (lobectomy and pneumonectomy), number of positive LNs in classification one $(1,2,3,4,5,6,7, \geq 8$ and number unspecified), and classification two $(\leq 3 \mathrm{v} .>3$, number unspecified excluded). Information on margin status, use of adjuvant chemotherapy, and specific radiotherapy technique (dose, beam energy, and so on) was not available with the SEER database and is no included in the analysis. Patients were divided into no postoperative radiotherapy (PORT) and postoperative radiotherapy groups according to whether they underwent postoperative radiotherapy.

\section{Statistical analysis}

The Pearson $\mathrm{X} 2$ test was used to analyze categoric variables. We used Kaplan-Meier method to determine OS and LCSS for patients underwent PORT or not. The log-rank test was used to compare the survival curves between Port and No PORT groups. Multivariable Cox proportional hazards models were used to calculate adjusted hazard ratios (HRs) and their 95\% CIs relating to the variables as described. Results were considered to be statistically significant when $P<0.05$. All data were analyzed using the SPSS 22.0 (SPSS, Chicago, IL), and the survival curve was drawn with GraphPad Prism 5.0 (GraphPad Software, San Diego, CA).

\section{Results}

\section{Baseline characteristics and outcomes}

A total of 3377 stage IIIA (N2) NSCLC patients with positive LNs were included in overall survival analysis, and 3077 patients were included in lung cancer-specific survival analysis. In the OS analysis, comparative treatment strategy was PORT in 1198 patients (35.5\%) and no PORT in 2179 (64.5\%). In the LCSS analysis, 1094 patients (35.6\%) and 1983 (64.4\%) underwent PORT and no PORT separately. Table 1 details the baseline characteristics. According to the results illustrated above, PORT was less performed in stage IIIA (N2) NSCLC patients, especially in elderly patients. And patients underwent lobectomy constitute the vast majority of included patients. Additionally, no significance differences emerged in sex, race location, tumor size, $\mathrm{T}$ stages, laterality and histology between PORT and No PORT patients.

The survival analysis by Kaplan-Meier plots showed that PORT was significantly associated with better OS (log-rank test, $p=0.0013)$ and LCSS (log-rank test, $p=$ 0.0094) for all NSCLC patients (Fig. 2a and b). These results were similar to E, Lally's study [4].
The Cox proportional hazard regression analyses (Additional file 1: Table S1) then demonstrated that older age, T2 stage, T3 stage, 4 positive LNs, 5 positive LNs, 6 positive LNs, 7 positive LNs and $\geq 8$ positive LNs had negative impacts on survival. Additionally, results showed that patients benefited from PORT significantly (OS: $\mathrm{HR}=0.854,95 \% \mathrm{CI}, 0.76$ to $0.941, P=0.001$; LCSS: $\mathrm{HR}=0.855,95 \% \mathrm{CI}, 0.769$ to $0.95, \mathrm{P}=0.004$ ).

Based on the preliminary analysis shown above, we combined the number of positive LNs categories $(1,2,3$, $4,5,6,7, \geq 8$ and number unspecified) into three kinds $(\leq 3,>3$ and number unspecified). The Cox proportional hazard regression analyses (Additional file 1: Table S2) demonstrated that older age (OS: $\mathrm{HR}=1.407 ; 95 \% \mathrm{CI}$, 1.281 to $1.545 ; P<0.001$; LCSS: $\mathrm{HR}=1.428 ; 95 \% \mathrm{CI}$, 1.290 to $1.581 ; \mathrm{P}<0.001$ ), T2 stage (OS: $\mathrm{HR}=1.254 ; 95 \%$ CI, 1.082 to $1.453 ; P=0.003$; LCSS: $\mathrm{HR}=1.247 ; 95 \% \mathrm{CI}$, 1.061 to $1.466 ; \mathrm{P}=0.007)$ and $\mathrm{T} 3$ stage $(\mathrm{OS}: \mathrm{HR}=1.770$; 95\% CI, 1.461 to 2.144; $\mathrm{P}<0.001$; LCSS: $\mathrm{HR}=1.810$; $95 \%$ $\mathrm{CI}, 1.472$ to $2.225 ; \mathrm{P}<0.001)$ had a negative impact on survival. Notably, positive LNs $(n>3)$ was found independently associated with poorer survival (OS: $\mathrm{HR}=$ $1.379,95 \% \mathrm{CI}, 1.253$ to $1.519, \mathrm{P}<0.001$; LCSS: $\mathrm{HR}=$ $1.415,95 \% \mathrm{CI}, 1.274$ to $1.571, \mathrm{P}<0.001)$. In addition, patients still benefited from the use of PORT (OS: HR = $0.860,95 \% \mathrm{CI}, 0.781$ to $0.947, \mathrm{P}=0.002$; LCSS: $\mathrm{HR}=$ $0.862,95 \% \mathrm{CI}, 0.775$ to $0.957, \mathrm{P}=0.006)$ significantly.

\section{Comparison of positive lymph nodes $(n \leq 3$ and $n>3)$}

Subset characteristic analyses were then performed for patients classified by the number of positive LNs ( $\mathrm{n} \leq 3$ and $n>3$ ). Patients with unspecified number of positive LNs were excluded, and so 194 and 180 patients were excluded from the following OS and LCSS multivariable analyses. Additional file 1: Table S3 and Table S4 detailed the baseline characteristics of OS and LCSS. No significance differences emerged in sex, race location, tumor size, $\mathrm{T}$ stages, laterality and histology between two groups, except $\mathrm{T}$ stage categories in the No. $\leq 3$ group of LCSS patients' characteristic.

The survival analyses were also investigated based on positive LNs categories $(n \leq 3$ and $n>3)$. For patients with positive LNs $(\mathrm{n} \leq 3)$, no significant differences was observed in OS $(p=0.1435)$ and LCSS $(p=0.1227)$ (Fig. 3a and b). However, for patients with positive LNs $(\mathrm{n}>3)$, there was a significant difference in survival between PORT and No PORT both in OS $(p=0.0015)$ and LCSS ( $\mathrm{p}=0.0087$ ) (Fig. $3 \mathrm{c}$ and $\mathrm{d}$ ).

The Cox proportional hazards regression model (Table 2) was then applied to study the superiority of PORT in subgroups of positive LNs categories ( $\mathrm{n} \leq 3$ and $n>3)$. In the positive LNs $(n \leq 3)$ subgroup, the use of PORT did not have a significant impact on survival both in OS and LCSS (OS with No PORT vs. PORT: HR, 
Table 1 Baseline Characteristics of Patients with stage IIIA pN2 status NSCLC

\begin{tabular}{|c|c|c|c|c|c|c|}
\hline \multirow[b]{3}{*}{ Demographic } & \multicolumn{3}{|c|}{ Baseline Characteristics of Patients in OS analysis } & \multicolumn{3}{|c|}{ Baseline Characteristics of Patients in LCSS analysis } \\
\hline & \multicolumn{2}{|c|}{ No.(\%) of Patients $(n=3377)$} & \multirow[b]{2}{*}{$P$ Value for $x 2$} & \multicolumn{2}{|c|}{ No.(\%) of Patients $(n=3077)$} & \multirow[b]{2}{*}{$P$ Value for $x^{2}$} \\
\hline & No Port $(n=2179)$ & Port $(n=1198)$ & & No Port $(n=1983)$ & Port $(n=1094)$ & \\
\hline \multicolumn{7}{|l|}{ Age at diagnosis, years } \\
\hline$<65$ & $887(40.7 \%)$ & $619(51.7 \%)$ & $<0.001$ & $829(41.8 \%)$ & $573(52.4 \%)$ & $<0.001$ \\
\hline$\geq 65$ & $1292(59.3 \%)$ & $579(48.3 \%)$ & & $1154(58.2 \%)$ & $521(47.6 \%)$ & \\
\hline \multicolumn{7}{|l|}{ Sex } \\
\hline Male & $1108(50.4 \%)$ & $605(50.5 \%)$ & 0.846 & $996(50.2 \%)$ & $539(49.3 \%)$ & 0.611 \\
\hline Female & $1071(49.6 \%)$ & $593(49.5 \%)$ & & $987(49.8 \%)$ & $555(50.7 \%)$ & \\
\hline \multicolumn{7}{|l|}{ Race } \\
\hline White & $1789(82.1 \%)$ & $967(80.7 \%)$ & 0.564 & 1624(81.9\%) & $882(80.6 \%)$ & 0.622 \\
\hline Black & $209(9.6 \%)$ & $120(10.0 \%)$ & & 193(9.7\%) & $110(10.1 \%)$ & \\
\hline Other & $181(8.3 \%)$ & $111(9.3 \%)$ & & $166(8.4 \%)$ & 102(9.3\%) & \\
\hline \multicolumn{7}{|l|}{ Location } \\
\hline Main bronchus & $28(1.3 \%)$ & $14(1.2 \%)$ & 0.106 & $27(1.4 \%)$ & $11(1.0 \%)$ & 0.186 \\
\hline Upper lobe & $1221(56.0 \%)$ & $728(60.8 \%)$ & & $1116(56.3 \%)$ & $663(60.6 \%)$ & \\
\hline Middle lobe & $102(4.7 \%)$ & $56(4.7 \%)$ & & $93(4.7 \%)$ & $52(4.8 \%)$ & \\
\hline Lower lobe & 760 (34.9\%) & $366(30.5 \%)$ & & $683(34.4 \%)$ & $336(30.7 \%)$ & \\
\hline Overlapping/lung, NOS & $68(3.1 \%)$ & $34(2.8 \%)$ & & $64(3.2 \%)$ & $32(2.9 \%)$ & \\
\hline \multicolumn{7}{|l|}{ Tumor size, $\mathrm{cm}$} \\
\hline$\leq 3.0$ & $939(43.1 \%)$ & $507(42.3 \%)$ & 0.805 & $849(42.8 \%)$ & $464(42.4 \%)$ & 0.73 \\
\hline 3.1 to 5.0 & $711(32.6 \%)$ & $402(33.6 \%)$ & & $645(32.5 \%)$ & $370(33.8 \%)$ & \\
\hline 5.1 to 7.0 & $323(14.8 \%)$ & $168(14.0 \%)$ & & $301(15.2 \%)$ & $153(14.0 \%)$ & \\
\hline$\geq 7.1$ & $161(7.4 \%)$ & 99 (8.3\%) & & $144(7.3 \%)$ & $87(8.0 \%)$ & \\
\hline Unknown & $45(2.1 \%)$ & $22(1.8 \%)$ & & $44(2.2 \%)$ & $20(1.8 \%)$ & \\
\hline \multicolumn{7}{|l|}{ T stage } \\
\hline $\mathrm{T} 1$ & $611(28.0 \%)$ & $326(27.2 \%)$ & 0.155 & $550(27.7 \%)$ & $299(27.3 \%)$ & 0.355 \\
\hline $\mathrm{T} 2$ & 1305 (59.9\%) & 701 (58.5\%) & & $1181(59.6 \%)$ & $638(58.3 \%)$ & \\
\hline T3 & 244 (11.2\%) & $164(13.7 \%)$ & & $233(11.7 \%)$ & $150(13.7 \%)$ & \\
\hline TX & $19(0.9 \%)$ & $7(0.6 \%)$ & & 19(1.0\%) & $7(0.7 \%)$ & \\
\hline \multicolumn{7}{|l|}{ Laterality } \\
\hline Right & $1206(55.3 \%)$ & $687(57.4 \%)$ & 0.241 & $1101(55.5 \%)$ & $640(58.6 \%)$ & 0.098 \\
\hline Left & $973(44.7 \%)$ & $509(42.6 \%)$ & & $882(44.5 \%)$ & $452(41.4 \%)$ & \\
\hline Unspecified & / & 2 & & / & 2 & \\
\hline \multicolumn{7}{|l|}{ Histology } \\
\hline Non-small cell carcinoma & $141(6.5 \%)$ & $81(6.8 \%)$ & 0.113 & $128(6.5 \%)$ & $71(6.5 \%)$ & 0.076 \\
\hline Adenocarcinoma, NOS & $1366(62.7 \%)$ & $795(66.4 \%)$ & & $1251(63.1 \%)$ & $738(67.4 \%)$ & \\
\hline Squamous cell carcinoma, NOS & 609 (27.9\&) & $294(24.5 \%)$ & & $546(27.5 \%)$ & $259(23.7 \%)$ & \\
\hline Large cell carcinoma, NOS & $63(2.9 \%)$ & $28(2.3 \%)$ & & $58(2.9 \%)$ & $26(2.4 \%)$ & \\
\hline \multicolumn{7}{|l|}{ Surgery type } \\
\hline Lobectomy & $1894(86.9 \%)$ & 1087 (90.7\%) & 0.001 & $1719(86.7 \%)$ & $999(91.3 \%)$ & $<0.001$ \\
\hline Pneumonectomy & $285(13.1 \%)$ & $111(9.3 \%)$ & & $264(13.3 \%)$ & $95(8.7 \%)$ & \\
\hline \multicolumn{7}{|l|}{ Number of positive lymph nodes } \\
\hline 1 & $655(30.1 \%)$ & $286(23.9 \%)$ & $<0.001$ & $588(29.7 \%)$ & $263(24.1 \%)$ & 0.009 \\
\hline 2 & 426 (19.6\%) & $212(17.7 \%)$ & & $386(19.5 \%)$ & 194(17.7\%) & \\
\hline
\end{tabular}


Table 1 Baseline Characteristics of Patients with stage IIIA pN2 status NSCLC (Continued)

\begin{tabular}{|c|c|c|c|c|c|c|}
\hline \multirow[b]{3}{*}{ Demographic } & \multicolumn{3}{|c|}{ Baseline Characteristics of Patients in OS analysis } & \multicolumn{3}{|c|}{ Baseline Characteristics of Patients in LCSS analysis } \\
\hline & \multicolumn{2}{|c|}{ No.(\%) of Patients $(n=3377)$} & \multirow[b]{2}{*}{$P$ Value for $x^{2}$} & \multicolumn{2}{|c|}{ No.(\%) of Patients ( $n=3077$ ) } & \multirow[b]{2}{*}{$P$ Value for $\times 2$} \\
\hline & No Port $(n=2179)$ & Port $(n=1198)$ & & No Port $(n=1983)$ & Port $(n=1094)$ & \\
\hline 3 & $278(12.8 \%)$ & $173(14.4 \%)$ & & $253(12.8 \%)$ & $156(14.3 \%)$ & \\
\hline 4 & $198(9.1 \%)$ & $116(9.7 \%)$ & & $183(9.2 \%)$ & 103(9.4\%) & \\
\hline 5 & $135(6.2 \%)$ & 103(8.6\%) & & 124(6.3\%) & $96(8.8 \%)$ & \\
\hline 6 & $101(4.6 \%)$ & $59(4.9 \%)$ & & $92(4.6 \%)$ & $54(4.9 \%)$ & \\
\hline 7 & $62(2.8 \%)$ & $41(3.4 \%)$ & & $56(2.8 \%)$ & $35(3.2 \%)$ & \\
\hline$\geq 8$ & $200(9.2 \%)$ & $138(11.5 \%)$ & & 187(9.4\%) & $127(11.6 \%)$ & \\
\hline No. of unspecified & 124(5.9\%) & $70(5.9 \%)$ & & 114(5.7\%) & $66(6.0 \%)$ & \\
\hline \multicolumn{7}{|l|}{ Number of positive lymph nodes } \\
\hline$\leq 3$ & $1359(66.1 \%)$ & $671(59.5 \%)$ & $<0.001$ & $1227(65.7 \%)$ & $613(59.6 \%)$ & 0.001 \\
\hline > 3 (Unspecified Excluded) & $696(33.9 \%)$ & $457(40.5 \%)$ & & $642(34.3 \%)$ & $415(40.4 \%)$ & \\
\hline
\end{tabular}

Abbreviations: NSCLC non-small cell lung cancer, OS overall survival, LCSS lung cancer-specific survival, NOS not otherwise specified

0.887; 95\% CI, 0.778 to $1.011 ; \mathrm{p}=0.072$; LCSS with No PORT vs. PORT: HR, 0.897; 95\% CI, 0.774 to 1.033 ; $\mathrm{p}=$ $0 \cdot 129)$. In positive LNs $(n>3)$, the use of PORT was associated with an improved statistical survival both in OS and LCSS (OS with No PORT vs. PORT: HR, 0.803; 95\% CI, 0.687 to $0.938 ; \mathrm{p}=0.006$; LCSS with No PORT vs. PORT: HR, 0.794; 95\% CI, 0.671 to $0.94 ; \mathrm{p}=0.007$ ).

\section{Discussion}

Through a large population-based cohort based on SEER database, we investigated whether the use of PORT will improve the prognosis of patients examined rare LNs metastasis. We detected age, race, sex, primary site, histology and so on when analyzing both OS and LCSS in pooled analysis. The outcomes of multivariable analyses demonstrated that the number of positive LNs and the use of PORT were independent risk factors. Patients with positive lymph more than 3 were found with poorer survival, and the use of PORT benefited patients significantly. These independent risk results were similar to a previous SEER based study and a retrospective study $[4,11]$. In order to detect how the number of positive LNs influences the OS and LCSS after the use of PORT, we assigned patients into positive LNs $(n \leq 3)$ group and positive LNs $(n>3)$ group according to the hazard ratios of each number category. Consequently, Kaplan-Meier curves and the cox proportional hazards regression models all demonstrated that the use of PORT significant improves survival for the patients with positive LNs $(n>3)$. And PORT was found not associated with the survival benefit in patients with positive LNs $(n \leq 3)$.

The SEER data are retrospectively collected, so the potential for error or bias may exist. We recognize that confounding factors, such as margin status and performance status, may influence the treating physician's decision to recommend the use of PORT. This information is not available for analysis, and an estimated $1 \%$ to $17 \%$ of surgical resections could still result in positive surgical margins [12]. So we only selected patients underwent lobectomy or pneumonectomy to avoid the positive margin status bias as much as possible. In addition, patients underwent lobectomy or pneumonectomy tend to have a better performance status than those who taken partial, wedge or segmental resection. Details about the lymph resection are also not available in the database. According to NCCN guidelines, resection is considered
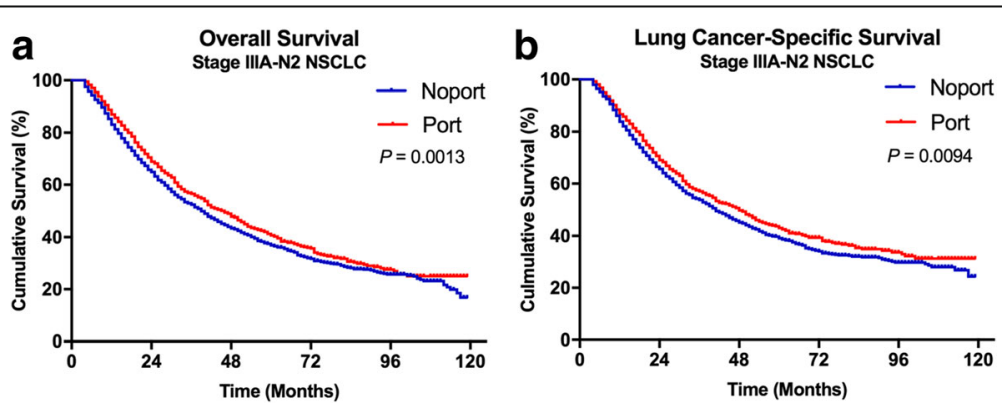

Fig. 2 Overall and lung cancer-specific survivals in patients with stage IIIA pN2 status non-small cell lung cancer (NSCLC) undergoing No PORT or PORT (a and $\mathbf{b}$ ). Abbreviations: PORT, Postoperative radiation. NSCLC, Non-small cell lung cancer 

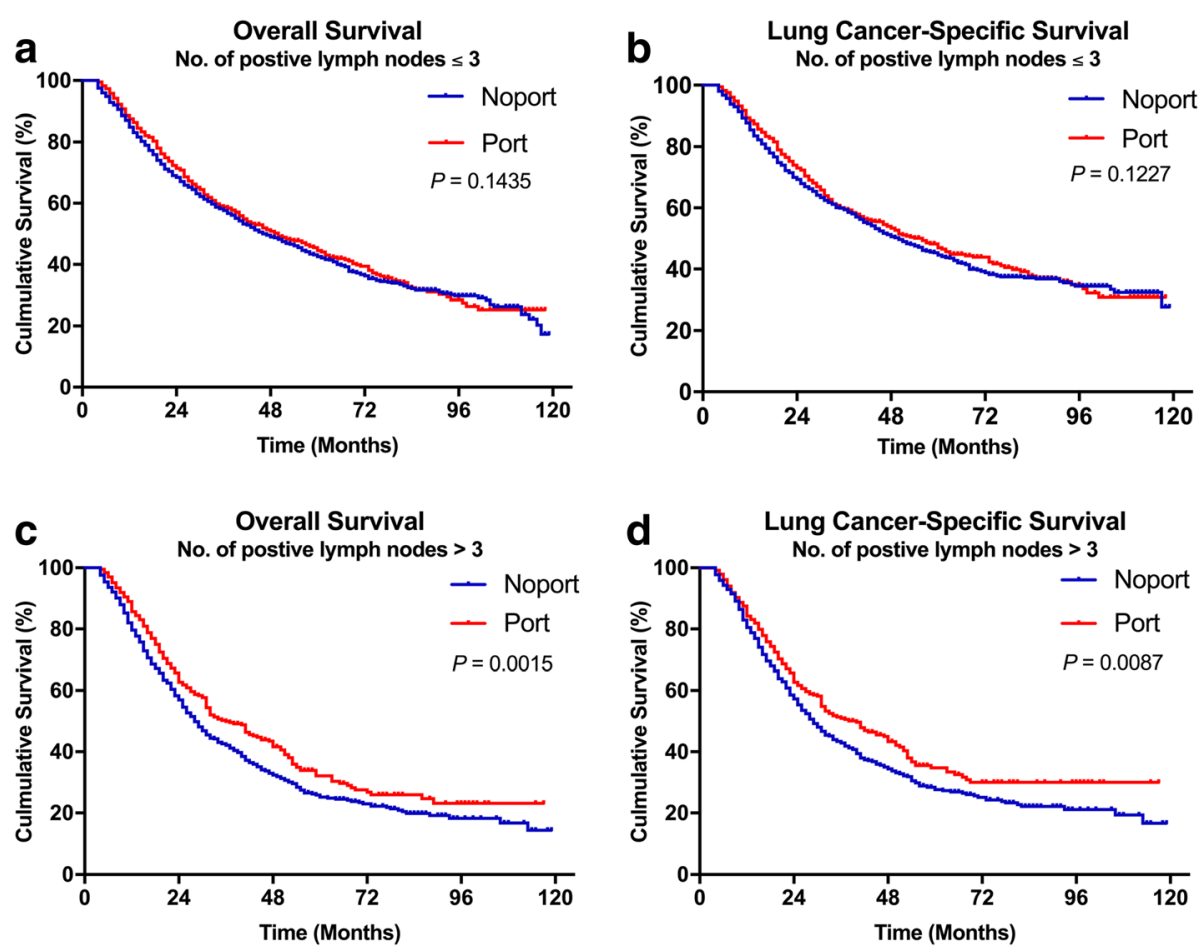

Fig. 3 Overall and lung cancer-specific survivals in stage IIIA-pN2 patients with the exact number of positive lymph nodes $\leq 3$ (a and $\mathbf{b}$ ) or $>3$ (c and d) undergoing No PORT or PORT. Abbreviations: PORT, Postoperative radiation. NSCLC, Non-small cell lung cancer

not appropriate for patients with multiple pathologically proven malignant LNs greater than $3 \mathrm{~cm}$, so those patients with fusion or huge malignant LNs could have been be excluded after patient selection. Considering more than 3000 patients were included in this study, we hoped that the impact of the incomplete LNs resection could be minimized.

To date, SEER database does not provide the data of adjuvant chemotherapy or target therapy, and SEERMedicare database does not open to the users outside the United States. Although preoperative adjuvant chemotherapy is now considered the standard treatment for resectable pN2 status patients, more detail data is still need for the further research. For patients with PORT, details of the dose, range and the dose per fraction are not available as well. Presently, the standard PORT dose and dose per fraction were considered less than 54 Gy and 2 Gy respectively $[6,13]$. According to the latest NCCN guide lines, the total dose of PORT was recommended no more than 60 Gy and the dose per faction was recommended less than 2Gy. 50-54Gy was recommended for negative margins and 54-60Gy was recommended for extracapsular nodal extension or microscopic positive margins in guide lines. According to a previous SEER and National Cancer Data Base (NCDB) pooled analysis, NCDB contains data not available in SEER database, such as chemotherapy and RT dose. And the results demonstrated that the range of radiotherapy dose is from 45 to 82.8 Gy and the median dose is 54 Gy after screening patients [14]. Therefore, we only included patients underwent lobectomy or pneumonectomy to reduce the heterogeneity of radiotherapy stems from positive margins and different performance status.

\section{Conclusions}

In summary, results from our study demonstrated that the exact number of positive LNs in ipsilateral mediastinal nodal resection has an impact on survival for stage IIIA pN2 patients with PORT. Although there were biases in lacking the details of adjuvant chemotherapy and postoperative radiotherapy, standard chemotherapy regiments and modern radiation technology could minimize these biases. To our knowledge, PORT was deemed detrimental for patients with N0 or N1 nodal disease because of the increased rate of intercurrent deaths $[4,15,16]$. One explanation is undetected microscopic/residual is less in N0 and N1 disease, so the benefit gained by treatment with PORT is diminished from the radiation toxicity [4]. For pN2 nodal status, there is a larger lymphatic metastasis of disease compared with NO or $\mathrm{N} 1$, so the use of PORT is often recommended. According to our results, different number of positive 
Table 2 Cox Proportional Hazards Regression Model for Overall Survival and Lung Cancer-Specific Survival in Patients based on Number Categories

\begin{tabular}{|c|c|c|c|c|c|c|c|c|}
\hline \multirow[b]{3}{*}{ Variable } & \multicolumn{4}{|c|}{ No. of positive lymph nodes $\leq 3$} & \multicolumn{4}{|c|}{ No. of positive lymph nodes $>3$} \\
\hline & \multicolumn{2}{|l|}{ Overall Survival } & \multicolumn{2}{|l|}{$\begin{array}{l}\text { Lung Cancer-Specific } \\
\text { Survival }\end{array}$} & \multicolumn{2}{|l|}{ Overall Survival } & \multicolumn{2}{|l|}{$\begin{array}{l}\text { Lung Cancer-Specific } \\
\text { Survival }\end{array}$} \\
\hline & Hazard Ratio $(95 \% \mathrm{Cl})$ & $p$ & Hazard Ratio $(95 \% \mathrm{Cl})$ & $p$ & Hazard Ratio $(95 \% \mathrm{Cl})$ & $p$ & Hazard Ratio $(95 \% \mathrm{Cl})$ & $p$ \\
\hline \multicolumn{9}{|l|}{ Age, years } \\
\hline$<65$ & 1.00 (reference) & & 1.00 (reference) & & 1.00 (reference) & & 1.00 (reference) & \\
\hline$\geq 65$ & $1.449(1.279$ to 1.643$)$ & $<0.001$ & $1.469(1.281$ to 1.684$)$ & $<0.001$ & $1.345(1.152$ to 1.572$)$ & $<0.001$ & $1.381(1.168$ to 1.632$)$ & $<0.001$ \\
\hline Race & & 0.234 & & 0.396 & & 0.054 & & 0.068 \\
\hline White & 1.00 (reference) & & 1.00 (reference) & & 1.00 (reference) & & 1.00 (reference) & \\
\hline Black & $1.030(0.849$ to 1.249$)$ & 0.768 & $1.012(0.817$ to 1.255$)$ & 0.91 & $0.739(0.547$ to 0.998$)$ & 0.048 & $0.757(0.557$ to 1.031$)$ & 0.077 \\
\hline Other & $0.832(0.668$ to 1.037$)$ & 0.102 & $0.849(0.667$ to 1.08$))$ & 0.182 & $0.802(0.606$ to 1.061$)$ & 0.122 & $0.776(0.572$ to 1.052$)$ & 0.103 \\
\hline \multicolumn{9}{|l|}{ Sex } \\
\hline Female & 1.00 (reference) & & 1.00 (reference) & & 1.00 (reference) & & 1.00 (reference) & \\
\hline Male & $1.349(1.191$ to 1.528$)$ & $<0.001$ & $1.366(1.192$ to 1.567$)$ & $<0.001$ & $1.308(1.122$ to 1.525$)$ & 0.001 & $1.279(1.085$ to 1.507$)$ & 0.003 \\
\hline Primary Site & & 0.705 & & 0.963 & & 0.993 & & 0.976 \\
\hline Main bronchus & 1.00 (reference) & & 1.00 (reference) & & 1.00 (reference) & & 1.00 (reference) & \\
\hline Upper lobe & $1.189(0.634$ to 2.230$)$ & 0.59 & $0.986(0.493$ to 1.969$)$ & 0.967 & $1.074(0.624$ to 1.85$)$ & 0.796 & $1.18(0.656$ to 2.121$)$ & 0.581 \\
\hline Middle lobe & $1.384(0.699$ to 2.739$)$ & 0.351 & $1.065(0.502$ to 2.26$)$ & 0.87 & $0.988(0.491$ to 1.988$)$ & 0.973 & $1.096(0.523$ to 2.3$)$ & 0.808 \\
\hline Lower lobe & $1.269(0.673$ to 2.394$)$ & 0.462 & $1.035(0.514$ to 2.084$)$ & 0.923 & $1.088(0.626$ to 1.892$)$ & 0.765 & $1.195(0.658$ to 2.172$)$ & 0.558 \\
\hline Overlapping/ lung, NOS & $1.241(0.616$ to 2.500$)$ & 0.545 & $1.021(0.474$ to 2.198$)$ & 0.957 & $1.055(0.535$ to 2.083$)$ & 0.876 & $1.124(0.548$ to 2.306$)$ & 0.749 \\
\hline Histology & & 0.11 & & 0.043 & & 0.152 & & 0.13 \\
\hline Non-small cell carcinoma & 1.00 (reference) & & 1.00 (reference) & & 1.00 (reference) & & 1.00 (reference) & \\
\hline Adenocarcinoma, NOS & $0.888(0.701$ to 1.125$)$ & 0.325 & $0.861(0.665$ to 1.115$)$ & 0.257 & $1.129(0.836$ to 1.525$)$ & 0.428 & $1.222(0.876$ to 1.705$)$ & 0.237 \\
\hline $\begin{array}{l}\text { Squamous cell carcinoma, } \\
\text { NOS }\end{array}$ & $1.121(0.874$ to 1.437$)$ & 0.368 & $1.047(0.797$ to 1.375$)$ & 0.741 & $1.248(0.905$ to 1.722$)$ & 0.177 & $1.456(1.018$ to 2.081$)$ & 0.039 \\
\hline $\begin{array}{l}\text { Large cell carcinoma, } \\
\text { NOS }\end{array}$ & $1.12(0.765$ to 1.64$)$ & 0.561 & $1.16(0.779$ to 1.729$)$ & 0.465 & $1.778(0.867$ to 3.122$)$ & 0.045 & $1.536(0.795$ to 2.966$)$ & 0.201 \\
\hline \multicolumn{9}{|l|}{ Laterality } \\
\hline Left & 1.00 (reference) & & 1.00 (reference) & & 1.00 (reference) & & 1.00 (reference) & \\
\hline Right & $0.985(0.871$ to 1.114$)$ & 0.809 & $1.008(0.88$ to 1.154$)$ & 0.911 & $1.012(0.867$ to 1.18$)$ & 0.882 & $1.05(0.889$ to 1.239$)$ & 0.568 \\
\hline Tumor Size & & 0.66 & & 0.724 & & 0.463 & & 0.5 \\
\hline$\leq 3.0$ & 1.00 (reference) & & 1.00 (reference) & & 1.00 (reference) & & 1.00 (reference) & \\
\hline $3.1-5.0$ & $1.008(0.838$ to 1.213$)$ & 0.93 & $1.045(0.854$ to 1.385$)$ & 0.671 & $1.068(0.849$ to 1.343$)$ & 0.575 & $1.061(0.827$ to 1.36$)$ & 0.641 \\
\hline $5.1-7.0$ & $1.03(0.825$ to 1.286$)$ & 0.793 & $1.088(0.854$ to 1.385$)$ & 0.495 & $1.146(0.879$ to 1.496$)$ & 0.314 & $1.13(0.85$ to 1.503$)$ & 0.4 \\
\hline$\geq 7.1$ & $0.879(0.661$ to 1.168$)$ & 0.374 & $0.936(0.684$ to 1.28$)$ & 0.678 & $1.216(0.888$ to 1.665$)$ & 0.222 & $1.256(0.892$ to 1.767$)$ & 0.192 \\
\hline Unknown & $1.297(0.766$ to 2.196$)$ & 0.332 & $1.344(0.765$ to 2.362$)$ & 0.304 & $0.66(0.302$ to 1.44$)$ & 0.296 & $0.692(0.316$ to 1.515$)$ & 0.357 \\
\hline T stage & & 0.001 & & 0.001 & & 0.003 & & 0.005 \\
\hline $\mathrm{T} 1$ & 1.00 (reference) & & 1.00 (reference) & & 1.00 (reference) & & 1.00 (reference) & \\
\hline $\mathrm{T} 2$ & $1.296(1.072$ to 1.566$)$ & 0.007 & $1.279(1.037$ to 1.578$)$ & 0.022 & $1.207(0.933$ to 1.562$)$ & 0.151 & $1.223(0.925$ to 1.616$)$ & 0.157 \\
\hline $\mathrm{T} 3$ & $1.722(1.324$ to 2.239$)$ & $<0.001$ & $1.79(1.348$ to 2.375$)$ & $<0.001$ & $1.769(1.291$ to 2.423$)$ & $<0.001$ & $1.793(1.279$ to 2.514$)$ & 0.001 \\
\hline Tx & $1.028(0.404$ to 2.614$)$ & 0.954 & $1.11(0.43$ to 2.87$)$ & 0.829 & $1.172(0.312$ to 4.412$)$ & 0.814 & $1.242(0.329$ to 4.697$)$ & 0.749 \\
\hline No. of positive lymph code ${ }^{a}$ & & 0.389 & & 0.17 & & 0.074 & & 0.075 \\
\hline $1 / 4$ & 1.00 (reference) & & 1.00 (reference) & & 1.00 (reference) & & 1.00 (reference) & \\
\hline $2 / 5$ & $1.038(0.902$ to 1.194$)$ & 0.601 & $1.032(0.884$ to 1.205$)$ & 0.689 & $1.288(1.035$ to 1.604$)$ & 0.024 & $1.316(1.039$ to 1.668$)$ & 0.023 \\
\hline $3 / 6$ & $1.113(0.955$ to 1.297$)$ & 0.169 & $1.172(0.991$ to 1.387$)$ & 0.064 & $1.197(0.937$ to 1.528$)$ & 0.15 & $1.24(0.952$ to 1.616$)$ & 0.111 \\
\hline$\geq 7$ & & & & & $1.255(1.036$ to 1.52$)$ & 0.02 & $1.275(1.036$ to 1.569$)$ & 0.022 \\
\hline
\end{tabular}


Table 2 Cox Proportional Hazards Regression Model for Overall Survival and Lung Cancer-Specific Survival in Patients based on Number Categories (Continued)

\begin{tabular}{|c|c|c|c|c|c|c|c|c|}
\hline \multirow[b]{3}{*}{ Variable } & \multicolumn{4}{|c|}{ No. of positive lymph nodes $\leq 3$} & \multicolumn{4}{|c|}{ No. of positive lymph nodes $>3$} \\
\hline & \multicolumn{2}{|l|}{ Overall Survival } & \multicolumn{2}{|l|}{$\begin{array}{l}\text { Lung Cancer-Specific } \\
\text { Survival }\end{array}$} & \multicolumn{2}{|l|}{ Overall Survival } & \multicolumn{2}{|l|}{$\begin{array}{l}\text { Lung Cancer-Specific } \\
\text { Survival }\end{array}$} \\
\hline & Hazard Ratio $(95 \% \mathrm{Cl})$ & $p$ & Hazard Ratio $(95 \% \mathrm{Cl})$ & $p$ & Hazard Ratio $(95 \% \mathrm{Cl})$ & $p$ & Hazard Ratio $(95 \% \mathrm{Cl})$ & $p$ \\
\hline \multicolumn{9}{|l|}{ Surgery type } \\
\hline Lobectomy & 1.00 (reference) & & 1.00 (reference) & & 1.00 (reference) & & 1.00 (reference) & \\
\hline Pneumonectomy & $1.101(0.884$ to 1.372$)$ & 0.391 & $1.056(0.822$ to 1.358$)$ & 0.669 & $0.986(0.791$ to 1.23$)$ & 0.903 & $1.025(0.812$ to 1.293$)$ & 0.836 \\
\hline \multicolumn{9}{|l|}{ Port } \\
\hline No & 1.00 (reference) & & 1.00 (reference) & & 1.00 (reference) & & 1.00 (reference) & \\
\hline Yes & $0.887(0.778$ to 1.011$)$ & 0.072 & $0.894(0.774$ to 1.033$)$ & 0.129 & $0.803(0.687$ to 0.938$)$ & 0.006 & $0.794(0.671$ to 0.94$)$ & 0.007 \\
\hline
\end{tabular}

Abbreviations: NOS not otherwise specified

a: $4,5,6, \geq 7$, these four categoric variables were designed for hazard ratios in the right two columns

LNs seem to have an impact on the survival benefit from the use of PORT. The results of LCSS analysis suggested a lower rate of recurrence for patients with more than 3 positive LNs, which could be considered the benefit from the PORT defeated the toxicity. All in all, we concluded that the number category is a strong independent prognostic factor in NSCLC and could add new information to the use of PORT in NSCLC pN2 status patients. Meanwhile, our results support the need to enroll patients on randomized controlled trials for the further analysis.

\section{Additional file}

Additional file 1: Table S1. Cox proportional hazards regression model for overall survival and lung cancer-specific survival in patients with stage IIIA pN2 status NSCLC. Abbreviations: NSCLC, Non-small cell lung cancer. NOS, Not Otherwise Specified. Table S2. Cox proportional hazards regression model for overall survival and lung cancer-specific survival in patients with stage IIIA pN2 status NSCLC. (No. of positive lymph nodes in two categories). Abbreviations: NSCLC, Non-small cell lung cancer. NOS, Not Otherwise Specified. Table S3. Baseline characteristics of Patients with NSCLC in overall survival analysis. *: 4, 5, 6, $\geq 7$, these four categoric variables were designed for the right two columns. Abbreviations: NSCLC, Non-small cell lung cancer. NOS, Not Otherwise Specified. Table S4. Baseline characteristics of Patients with NSCLC in lung cancer-specific survival analysis. *: 4, 5, 6, $\geq 7$, these four categoric variables were designed for the right two columns. Abbreviations: NSCLC, Non-small cell lung cancer. NOS, Not Otherwise Specified. (DOCX 68 kb)

\section{Abbreviations}

AJCC: American Association of Cancer; HRs: Hazard ratios; ICD-O3: International Classification of Diseases for Oncology, 3rd Edition: LCSS: Lung cancer-specific survival; LNs: Lymph nodes; LRR: Localregional recurrence; NCCN: National Comprehensive Cancer Network; NCDB: National Cancer Data Base; NOS: Not otherwise specified; NSCLC: Non-small cell lung cancer; OS: Overall survival; pN2: Pathological N2 status; PORT: Postoperative radiation; SEER: Surveillance, epidemiology, and end results; WHO: World Health Organization

\section{Acknowledgements}

Not applicable.

\section{Funding}

This study is founded by the Natural Science Foundation of China (81572261 to Lin Xu; 81672295 to Rong Yin; 81672294 to Feng Jiang), the Key Project of
Cutting-edge Clinical Technology of Jiangsu Province (BE2016797 to Lin Xu) and the Innovation Capability Development Project of Jiangsu Province (BM2015004 to Lin Xu).

\section{Availability of data and materials}

Data sharing not applicable to this article as no datasets were generated or analyzed during the current study.

\section{Authors' contributions}

Conception and design: SW, ZM, KX and LX. Collection and assembly of data: SW, XY, RC, MQ and YW. Data analysis and interpretation: SW, YX, WX and XY. Manuscript writing: SW and ZM. Final approval of manuscript: FJ, RY and LX. All authors read and approved the final manuscript.

Ethics approval and consent to participate

Not applicable.

\section{Consent for publication}

Not applicable.

\section{Competing interests}

The authors declare that they have no competing interests.

\section{Publisher's Note}

Springer Nature remains neutral with regard to jurisdictional claims in published maps and institutional affiliations.

\section{Author details}

${ }^{1}$ Department of Thoracic Surgery, Jiangsu Cancer Hospital \& Jiangsu Institute of Cancer Research \& Nanjing Medical University Affiliated Cancer Hospital, Jiangsu Key Laboratory of Molecular and Translational Cancer Research, Nanjing 210009, China. ${ }^{2}$ The Fourth Clinical College of Nanjing Medical University, Nanjing 210000, China. ${ }^{3}$ Department of Thoracic Surgery, Huai'an First People's Hospital, Nanjing Medical University, Huai'an 223300, China. ${ }^{4}$ Department of Cardiothoracic Surgery, Taixing People's Hospital, The Affiliated Taixing Hospital of Yangzhou University, Taixing 225400, China.

Received: 9 August 2017 Accepted: 18 December 2017

Published online: 29 December 2017

\section{References}

1. Ramnath N, Dilling TJ, Harris LJ, Kim AW, Michaud GC, Balekian AA, Diekemper R, Detterbeck FC, Arenberg DA. Treatment of stage III non-small cell lung cancer: diagnosis and management of lung cancer: American College of Chest Physicians evidence-based clinical practice guidelines. CHEST Journal. 2013;143(5 suppl):e314S-40S.

2. Le Péchoux C. Role of postoperative radiotherapy in resected non-small cell lung cancer: a reassessment based on new data. Oncologist. 2011;16(5): $672-81$. 
3. Group NM-aC. Adjuvant chemotherapy, with or without postoperative radiotherapy, in operable non-small-cell lung cancer: two meta-analyses of individual patient data. Lancet. 2010;375(9722):1267-77.

4. Lally BE, Zelterman D, Colasanto JM, Haffty BG, Detterbeck FC, Wilson LD. Postoperative radiotherapy for stage II or III non-small-cell lung cancer using the surveillance, epidemiology, and end results database. J Clin Oncol. 2006; 24(19):2998-3006.

5. Sawyer TE, Bonner JA, Gould PM, Foote RL, Deschamps C, Trastek VF, Pairolero PC, Allen MS, Lange CM, Li H. Effectiveness of postoperative irradiation in stage IIIA non-small cell lung cancer according to regression tree analyses of recurrence risks. Ann Thorac Surg. 1997;64(5):1402-7.

6. Machtay M, Lee JH, Shrager JB, Kaiser LR, Glatstein E. Risk of death from intercurrent disease is not excessively increased by modern postoperative radiotherapy for high-risk resected non-small-cell lung carcinoma. J Clin Oncol. 2001:19(19):3912-7.

7. Douillard J-Y, Rosell R, De Lena M, Riggi M, Hurteloup P, Mahe M-A, Association ANIT. Impact of postoperative radiation therapy on survival in patients with complete resection and stage I, II, or IIIA non-small-cell lung cancer treated with adjuvant chemotherapy: the adjuvant Navelbine international Trialist association (ANITA) randomized trial. Int J Radiat Oncol Biol Phys. 2008;72(3):695-701.

8. Group PM-aT. Postoperative radiotherapy for non-small cell lung cancer. Cochrane Database Syst Rev. 2005;(2):CD002142.

9. Surmont $\mathrm{V}$. Treatment advances in locally advanced and metastatic nonsmall cell. Lung Cancer. 2010. https://repub.eur.nl/pub/17725/.

10. Berardi R, Santinelli A, Brunelli A, Morgese F, Onofri A, Savini A, Caramanti M, Pompili C, Salati M, Zuccatosta L. Prognostic factors in early stage non-small cell lung cancer: the importance of number of Resected lymph nodes and vascular invasion. Chemotherapy: Open Access. 2013;2:120.

11. Fukui T, Mori S, Yokoi K, Mitsudomi T. Significance of the number of positive lymph nodes in Resected non-small cell lung cancer. J Thorac Oncol. 2006; 1(2):120-5.

12. Wang EH, Corso CD, Rutter CE, Park HS, Chen AB, Kim AW, Wilson LD, Decker RH, JB Y. Postoperative radiation therapy is associated with improved overall survival in incompletely Resected stage II and III nonsmall-cell lung cancer. J Clin Oncol. 2015;33(25):2727-34.

13. Dautzenberg B, Arriagada R, Boyer Chammard A, Jarema A, Mezzetti M, Mattson K, Lagrange JL, Le Pechoux C, Lebeau B, Chastang C. A controlled study of postoperative radiotherapy for patients with completely resected nonsmall cell lung carcinoma. Cancer. 1999;86(2):265-73.

14. Robinson CG, Patel AP, Bradley JD, DeWees T, Waqar SN, Morgensztern D, Baggstrom MQ, Govindan R, Bell JM, Guthrie TJ, et al. Postoperative radiotherapy for pathologic N2 non-small-cell lung cancer treated with adjuvant chemotherapy: a review of the National Cancer Data Base. J Clin Oncol. 2015;33(8):870-6.

15. Corso CD, Rutter CE, Wilson LD, Kim AW, Decker RH, Husain ZA. Reevaluation of the role of postoperative radiotherapy and the impact of radiation dose for non-small-cell lung cancer using the National Cancer Database. J Thorac Oncol. 2015;10(1):148-55.

16. Bogart JA, Aronowitz JN. Localized non-small cell lung cancer: adjuvant radiotherapy in the era of effective systemic therapy. Clin Cancer Res. 2005; 11(13):5004s-10s.

\section{Submit your next manuscript to BioMed Central and we will help you at every step:}

- We accept pre-submission inquiries

- Our selector tool helps you to find the most relevant journal

- We provide round the clock customer support

- Convenient online submission

- Thorough peer review

- Inclusion in PubMed and all major indexing services

- Maximum visibility for your research

Submit your manuscript at www.biomedcentral.com/submit
Biomed Central 